\title{
A EXPERIÊNCIA EDUCACIONAL NO ENSINO SUPERIOR E AS TECNOLOGIAS DIGITAIS MÓVEIS
}

\author{
AUTOR: WELLINGTON JESUS DOS SANTOS \\ CO-AUTOR/ORIENTADOR: IVANA MARIA GAMERMAN
}

Resumo: Dispositivos móveis são a grande marca da sociedade contemporânea estando presente em vários momentos de nossas vidas. Sua mobilidade permite acesso de qualquer lugar a qualquer momento, para os estudantes isso inclui a sala de aula, podendo causar distrações durante apresentação de conteúdo. Esse estudou buscou examinar se a distração causada pelo uso de dispositivos móveis afeta o desempenho acadêmico. Para isso foi conduzido um experimento em sala de aula dividida em três grupos, sendo dois na condição experimental; uso livre de dispositivos móveis e uso estimulado de dispositivos móveis; e grupo de controle (não uso de dispositivos móveis). O rendimento do grupo que não usou dispositivos móveis foi superior aos demais grupos. Afim de testar variáveis confundidoras foi aplicado um questionário sobre a motivação para estudar e um questionário com autorresposta sobre o tempo que julgam utilizar dispositivos móveis em sala de aula. As medidas das variáveis não influenciaram na aprendizagem.

Palavras-chave: Dispositivos Móveis, Performance acadêmica, Multitarefa. 